\title{
Kinetics of nanocrystalline iron nitriding
}

\author{
Walerian Arabczyk, Jacek Zamłynny, Dariusz Moszyński* \\ West Pomeranian University of Technology, Szczecin, Institute of Chemical and Environment Engineering, \\ ul. Pułaskiego 10,70-322 Szczecin, Poland \\ *Corresponding author: e-mail: dmoszynski@ps.pl
}

\begin{abstract}
Nitriding of nanocrystalline iron was studied under the atmosphere of pure ammonia and in the mixtures of ammonia - hydrogen - nitrogen at temperatures between $350^{\circ} \mathrm{C}$ and $500^{\circ} \mathrm{C}$ using thermogravimetry and $\mathrm{x}$-ray diffraction. Three stages of nitriding were observed and have been ascribed to the following schematic reactions: (1) $\alpha-\mathrm{Fe} \rightarrow \gamma^{\prime}-\mathrm{Fe}_{4} \mathrm{~N}$, (2) $\gamma^{\prime}-\mathrm{Fe}_{4} \mathrm{~N} \rightarrow \varepsilon-\mathrm{Fe}_{3} \mathrm{~N}$ and (3) $\varepsilon-\mathrm{Fe}_{3} \mathrm{~N} \rightarrow \varepsilon-\mathrm{Fe}_{2} \mathrm{~N}$. The products of these reactions appeared in the nitrided nanocrystalline iron not sequentially but co-existed at certain reaction ranges. The dependence of a reaction rate for each nitriding stage on partial pressure of ammonia is linear. Moreover, a minimal ammonia partial pressure is required to initiate the nitriding at each stage.
\end{abstract}

Keywords: iron nitrides, microporous materials, chemical synthesis, thermogravimetric analysis, X-ray diffraction.

\section{INTRODUCTION}

Nitriding of monolithic and coarse-grained iron has been a subject of extensive research ${ }^{\mathbf{1 - 3}}$ due to its influence on the surface hardness, anticorrosion properties and wear resistance of metallic materials. Recently, nanometric materials have attracted a lot of attention due to their exceptional properties ${ }^{4-7}$. In the iron-nitrogen system several different phases of iron nitrides can be distinguished. Among them the most important are $\gamma^{\prime}-\mathrm{Fe}_{4} \mathrm{~N}$ and $\varepsilon-\mathrm{Fe}_{\mathrm{x}} \mathrm{N}^{8}$. The preparation techniques of iron nitrides include a simple reaction between iron and gaseous ammonia ${ }^{5,7,9-11}$ as well as spark erosion, plasma nitriding, and other methods ${ }^{12-15}$. Thermodynamics ${ }^{16}$ and kinetics $^{17}$ of nitriding of the monolithic iron are well known. The exact composition of nitrided material depends on the nitriding temperature and the nitriding potential ${ }^{18}$. However, the knowledge that has been gathered for monolithic and coarse-grained materials is not fully applicable to the nanometric materials ${ }^{19}$. Recently, several new investigations on the nitriding of nanocrystalline iron have been published ${ }^{9}, 11,20-23$.

The present paper is focused on the kinetics of nanocrystalline iron nitriding process, based on the reaction between iron and gaseous ammonia. The process carried out in pure ammonia as well as ammonia - hydrogen - nitrogen mixtures have been investigated in the temperature range between $350^{\circ} \mathrm{C}$ and $500^{\circ} \mathrm{C}$. The studies are based on the thermogravimetric measurements accompanied with XRD analysis.

\section{EXPERIMENTAL}

Nanocrystalline iron samples have been prepared by a complex procedure consisting of fusion and reduction stages. At first an oxidized precursor was prepared by the fusion of magnetite with calcium and aluminum oxides in an electric furnace. The additives were introduced to promote the formation of the nanocrystalline structure of the samples. The obtained alloy consisted of iron oxides with a small addition of calcium oxide (3.2\%wt.) and aluminum oxide ( $3.3 \%$ wt.). The alloy was crashed and grains of size between 1 and $1.2 \mathrm{~mm}$ were selected. Before each nitriding experiment a new iron sample was prepared from the precursor. $1 \mathrm{~g}$ of the precursor grains was placed in a single layer on a perforated platinum basket being a part of an electronic spring thermobalance. Next, the reduction of iron oxides under the flow of pure hydrogen (99.999\%) was performed. It was done under atmospheric pressure, according to the following temperature program: 1 hour at $200^{\circ} \mathrm{C}, 2 \mathrm{~h}$ at $350^{\circ} \mathrm{C}, 12 \mathrm{~h}$ at $400^{\circ} \mathrm{C}, 24 \mathrm{~h}$ at $450^{\circ} \mathrm{C}, 24 \mathrm{~h}$ at $500^{\circ} \mathrm{C}$. The final weight loss observed for all the samples was about $25 \%$ wt., which agrees with theoretical calculations assuming the complete reduction of iron oxides.

Nitriding processes were carried out isothermally in a glass tube reactor being part of the electronic spring thermobalance, either under the atmosphere of pure ammonia or in various $\mathrm{NH}_{3} / \mathrm{N}_{2} / \mathrm{H}_{2}$ mixtures. The source of ammonia was a gas cylinder supplied by Messer Polska. The purity of the gas was $99.97 \%$ vol. $\mathrm{NH}_{3} / \mathrm{N}_{2} / \mathrm{H}_{2}$ mixtures were prepared by the catalytic decomposition of ammonia over a nickel catalyst placed in a pre-reactor. Various compositions of $\mathrm{NH}_{3} / \mathrm{N}_{2} / \mathrm{H}_{2}$ mixtures were obtained by the variation of the decomposition temperature in the pre-reactor. The flow of ammonia introduced to the process was regulated by a valve and measured with use of a flowmeter.

During thermogravimetric (TG) experiments the sample mass change as well as the reaction temperature were acquired at the computer. The concentration of nitrogen in iron samples was calculated assuming that no other reaction but iron nitriding took place in the solid. The composition of the gas at the outlet of the reactor was measured acidimetrically by the following procedure: the entire gas product stream was passed through a fritted gas bubbler with a magnetic stirrer containing a given volume of $0.1 \mathrm{M} \mathrm{HCl}$ with a droplet of phenolphthalein as long as a solution colour changed into light red. The concentration of ammonia in the gas was calculated basing on the amount of $\mathrm{NH}_{3}$ absorbed in the bubbler and a volume of the remaining gas mixture $\left(\mathrm{N}_{2}+\mathrm{H}_{2}\right)$ measured as a volume of water displaced from a vessel.

The porous iron samples were pyrophoric and cannot be exposed to air immediately after the completion of the reaction, therefore before the removal from the reactor the passivation procedure was always applied. The gas 
mixture remaining in the reactor was exchanged with the nitrogen stream saturated with water vapour by passing the gas through a bubbler filled with cold water. After this procedure the increase of the sample mass of about $4 \%$ wt. was observed. It was attributed to the formation of a very thin layer of superficial iron oxides.

The passivated samples were characterized by x-ray diffraction. The phase composition of the samples was examined with the use of HZG-4 diffractometer. Co K $\alpha$ radiation was used during the XRD experiments and the phase identification was carried out with the use of $\mathrm{X}$ Rayan software. The average size of crystallites was calculated according to Scherrer method. To complement the results of these calculations the TEM examination was carried out in JEOL JEM 1200 EX. The specific surface area of the samples was measured by the volumetric method by nitrogen adsorption with the use of Micromeritics ASAP 2010 apparatus.

\section{RESULTS AND DISCUSSION}

The substrate was prepared according to the procedure described above to obtain the grain-like form required in TG kinetic experiments and to get porous iron made of nanometric crystallites. The mean size of the substrate crystallites evaluated form XRD analysis is $30 \mathrm{~nm}$. TEM image shown in Fig. 1 displays a single iron particle of the iron substrate. The size of the particle is about $100 \mathrm{~nm}$. The surface area of iron substrate measured by the volumetric method is $22 \mathrm{~m}^{2} / \mathrm{g}$. Basing on the volumetric data

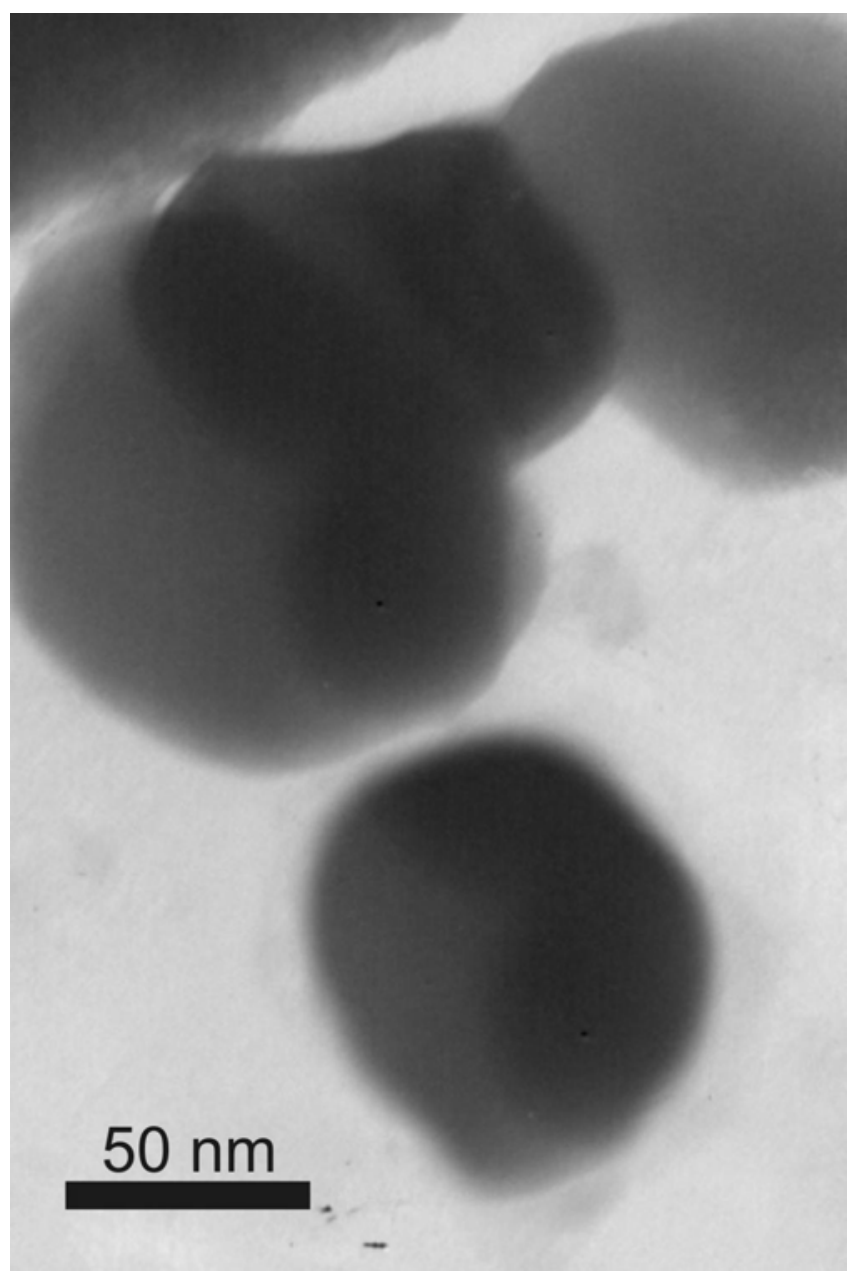

Figure 1. Transmission electron micrograph of iron particles in the iron substrate the particle size was calculated according to the model presented in Ref. 24, assuming that the particles were spherical. The resulting value is $36 \mathrm{~nm}$ and is in line with the XRD analysis. The discrepancy between the results obtained by XRD together with the volumetric analysis and TEM observations may be explained if one considers that the iron particles are built from smaller platelets as suggested by Schlögl'

In its final form iron substrate contained about $7 \%$ of additives $\left(\mathrm{Al}_{2} \mathrm{O}_{3}\right.$ and $\left.\mathrm{CaO}\right)$ required for the formation of its well-developed nanometric structure. Under the conditions of the nitriding experiments the reaction between the additives and ammonia was not expected. Therefore the total mass gain has been attributed to the increasing nitrogen concentration in the sample.

The process of nitriding was observed by thermogravimetric method. In Fig. 2 the TG curves recorded for two processes carried out at $350^{\circ} \mathrm{C}$ and $500^{\circ} \mathrm{C}$ are displayed. In both experiments pure ammonia was delivered to the reactor.

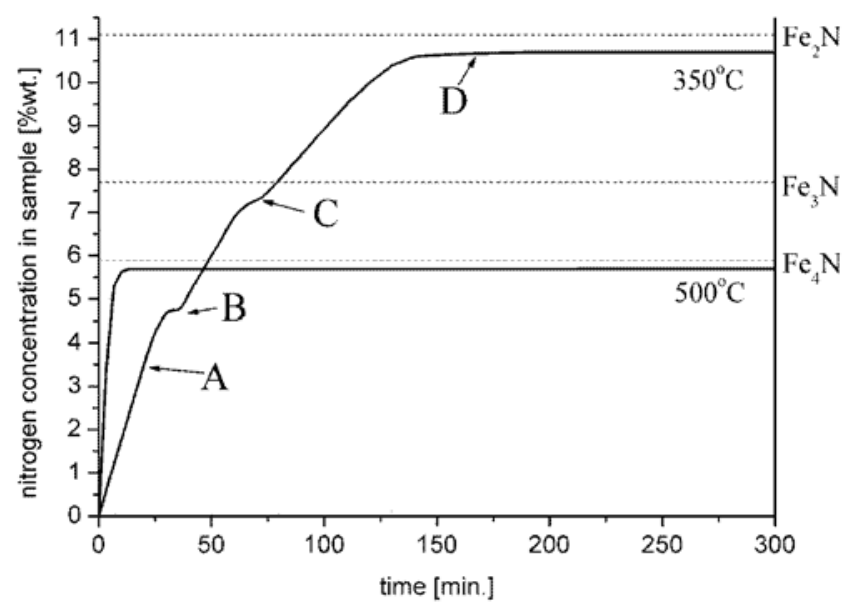

Figure 2. Termogravimetric curves of iron nitriding in pure ammonia at $350^{\circ} \mathrm{C}$ and $500^{\circ} \mathrm{C}$. Points $\mathrm{A}, \mathrm{B}, \mathrm{C}$ and $\mathrm{D}$ indicate the reaction stages at which samples were analyzed using XRD. Horizontal dashed lines represent the nitrogen concentration in the stoichiometric iron nitrides

The iron nitriding carried out at $500^{\circ} \mathrm{C}$ proceeds according to the line shown in Fig. 2. One stage of the reaction is observed and the final concentration of nitrogen corresponds well to the iron nitride $\mathrm{Fe}_{4} \mathrm{~N}$. An XRD analysis proved that almost pure $\gamma^{\prime}-\mathrm{Fe}_{4} \mathrm{~N}$ was formed (Fig. 3).

At $350^{\circ} \mathrm{C}$ three stages of the process may be clearly distinguished. During each of them the increase of the nitrogen concentration in the sample is approximately linear. The inflection points on the TC curve are notable and lie at about $4.7 \%$ wt., $7.5 \%$ wt. and $10.5 \%$ wt. of nitrogen in the sample (points B, C and D in Fig. 2). The nitrogen concentration at the inflection points is slightly lower than the concentration of nitrogen characteristic for stoichiometric iron nitrides: $\gamma^{\prime}-\mathrm{Fe}_{4} \mathrm{~N}, \varepsilon-\mathrm{Fe}_{3} \mathrm{~N}$ and $\varepsilon-\mathrm{Fe}_{2} \mathrm{~N}$, which are $5.9 \%$ wt., $7.7 \%$ wt. and $11.1 \%$ wt., respectively. This observation suggests that nitriding process at this temperature is stepwise and passes through three stages.

To get the information about the phase composition of the sample at a given reaction stage $\mathrm{x}$-ray diffraction analysis of the samples nitrided up to four characteristic con- 


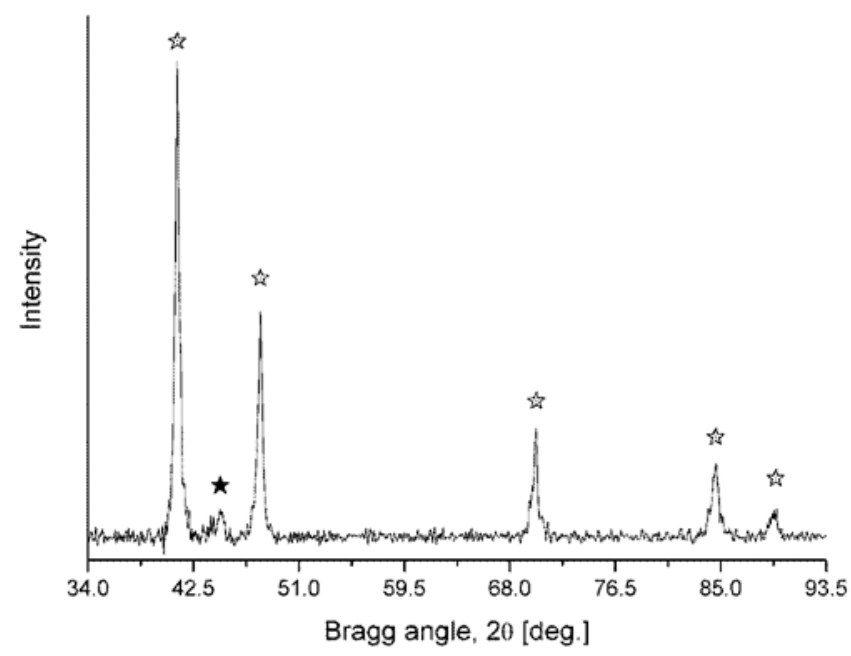

Figure 3. X-ray diffractogram of the final product of iron nitriding in pure ammonia at $500^{\circ} \mathrm{C}$. The identified phases are marked as follows: black star $-\alpha-F e$, open star $-\gamma^{\prime}-\mathrm{Fe}_{4} \mathrm{~N}$.

centrations (points A, B, C and D in Fig. 2) was carried out. At the point $\mathrm{A}$, when the nitrogen concentration reaches $3.5 \%$ wt. a mixture of two phases, $\alpha-\mathrm{Fe}$ and $\gamma^{\prime}-$ $\mathrm{Fe}_{4} \mathrm{~N}$ is observed (Fig. 4a). As expected, part of $\alpha-\mathrm{Fe}$ is converted into $\gamma^{\prime}-\mathrm{Fe}_{4} \mathrm{~N}$. No other phases are identified. At point $\mathrm{B}$, the first inflection point, the concentration of nitrogen in the sample is $4.7 \%$ wt. At this stage, $\alpha$ - Fe phase disappears and $\gamma^{\prime}-\mathrm{Fe}_{4} \mathrm{~N}$ dominates in the sample (Fig. 4b). However, another phase, $\varepsilon-\mathrm{Fe}_{\mathrm{x}} \mathrm{N}$, starts to emerge. It indicates that the formation of iron nitrides in nanocrystalline samples is not strictly sequential but rather reactions leading to the formation of different iron nitrides overlap partially. It should be noted that $\varepsilon-\mathrm{Fe}_{\mathrm{x}} \mathrm{N}$ occurs in the sample at the concentration of nitrogen lower than that corresponding with stoichiometric $\mathrm{Fe}_{4} \mathrm{~N}$. At point $\mathrm{C}$, when the concentration of nitrogen in the sample is $7.5 \%$ wt. the $\alpha$ - Fe crystallites are not observed anymore and $\varepsilon-\mathrm{Fe}_{\mathrm{x}} \mathrm{N}$ is the main component (Fig. 4c). Some rest of $\gamma^{\prime}-\mathrm{Fe}_{4} \mathrm{~N}$ can be identified. At this stage stoichiometry of the $\varepsilon-\mathrm{Fe}_{\mathrm{x}} \mathrm{N}$ phase is close to $\mathrm{Fe}_{3} \mathrm{~N}$. At the final stage of nitriding, at point $\mathrm{D}$, the concentration of nitrogen reaches $10.7 \%$ wt. The phase analysis indicates that the sequence of XRD reflexes is identical to that observed at point $\mathrm{C}$, however, the increasing shift of the reflexes' positions to the smaller $2 \theta$ values is observed (Fig. 4d). The shift suggests the expansion of the $\varepsilon-\mathrm{Fe}_{\mathrm{x}} \mathrm{N}$ lattice. At this stage of the process the stoichiometry of the product comes close to $\mathrm{Fe}_{2} \mathrm{~N}$.

The final concentration of nitrogen i.e. the type of iron nitride formed after the completion of nitriding process is a function of temperature and a nitriding potential, defined as $\ln \frac{p_{\mathrm{NH}_{3}}}{p_{\mathrm{H}_{2}}^{3 / 2}}{ }^{16,18}$. At $350^{\circ} \mathrm{C}$ when the process of nitriding achieved its final state the gas downstream of the sample contained almost pure ammonia. According to Lehrer diagram ${ }^{\mathbf{1 8}, \mathbf{2 6}}$, under these conditions $\varepsilon$-iron nitride is a stable phase as observed in the present experiments. Ammonia partial pressure at the outlet of the reactor during the experiments carried out at $500^{\circ} \mathrm{C}$ was only 0.68 bar. As a result, the material was exposed to the atmosphere which led to the formation of $\gamma^{\prime}-\mathrm{Fe}_{4} \mathrm{~N}$ only. The difference between gas compositions observed at various

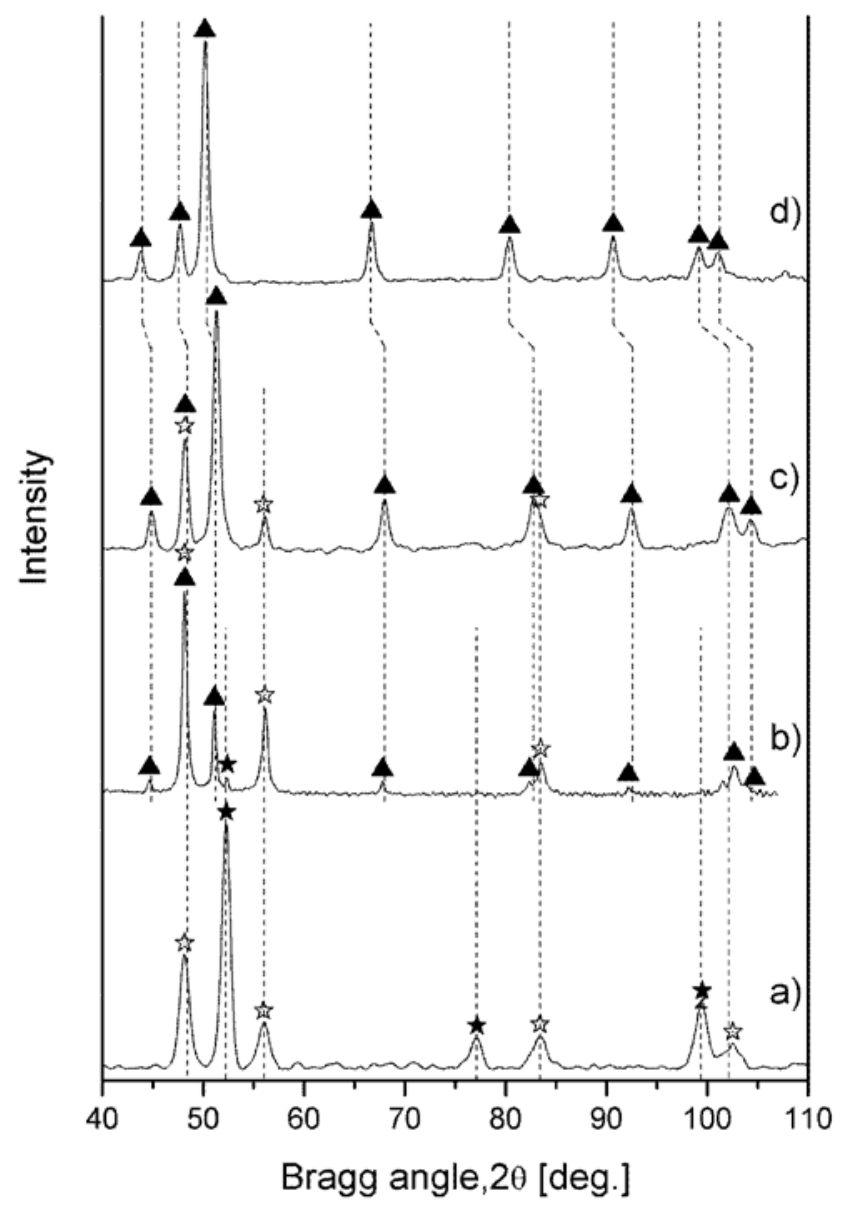

Figure 4. X-ray diffractograms for relevant stages of the reaction at $350^{\circ} \mathrm{C}$ shown in Fig. 1: a) point $\mathrm{A}, \mathrm{b}$ ) point $\mathrm{B}, \mathrm{c})$ point $\mathrm{C}$, d) point $\mathrm{D}$. The identified phases are marked as follows: black star $-\alpha-\mathrm{Fe}$, open star $-\gamma^{\prime}-\mathrm{Fe}_{4} \mathrm{~N}$, black triangle $-\varepsilon-\mathrm{Fe}_{\mathrm{x}} \mathrm{N}$

temperatures is due to the varying rates of ammonia decomposition process taking place on the iron sample $27-29$.

A plausible explanation of the multi-stage process observed at $350^{\circ} \mathrm{C}$ are three reactions schematically shown below:

$\alpha-\mathrm{Fe} \rightarrow \gamma^{\prime}-\mathrm{Fe}_{4} \mathrm{~N}$

$\gamma^{\prime}-\mathrm{Fe}_{4} \mathrm{~N} \rightarrow \varepsilon-\mathrm{Fe}_{3} \mathrm{~N}$

$\varepsilon-\mathrm{Fe}_{3} \mathrm{~N} \rightarrow \varepsilon-\mathrm{Fe}_{2} \mathrm{~N}$

Iron substrate is first converted into $\gamma^{\prime}-\mathrm{Fe}_{4} \mathrm{~N}$, which with the increasing concentration of nitrogen in the bulk transforms into $\varepsilon-\mathrm{Fe}_{\mathrm{x}} \mathrm{N}$. Depending on the nitrogen content the stoichiometry of the obtained compound varied between $\mathrm{Fe}_{3} \mathrm{~N}$ and $\mathrm{Fe}_{2} \mathrm{~N}$. This mechanism is supported both by TG and XRD observations. However, two consequences coming from the proposed mechanism disagree with the observations. First, according to the knowledge gained for nitriding of the coarse-grained materials the formation of iron nitrides is a process of nucleation and growth driven by diffusion ${ }^{6}$ and it follows the parabolic law ${ }^{5}$, which can be symbolically presented as $\Delta \mathrm{m}=\mathrm{A} \times \mathrm{t}^{0.5}$ where, $\Delta \mathrm{m}-$ mass gain, $\mathrm{t}$ - time of the reaction and $\mathrm{A}$ - constant. However, the TG observations show a rather linear dependence on each stage of the process, where the slope of the linear stages varies. Secondly, the mechanism indicates sequential reactions from iron substrate to iron nitrides, but XRD experiments clearly 
prove the coexistence of different iron nitrides in the samples.

To understand the presence of these discrepancies the nanocrystalline structure of the substrate must be considered. Recently it was shown that for the samples having nanocrystalline superficial structure the linear dependence on time is observed for nitriding kinetics ${ }^{5}$. Thanks to the much higher density of grain boundaries the intensified diffusivity of nitrogen and reactivity of iron atoms in the nanostructured iron material is suggested. In the case of the present study the whole material has the nanocrystalline structure and the diffusion length is very small. It is rather supposed that surface reaction of ammonia decomposition is a limiting step. This assumption would justify the linear kinetics of nitriding.

Consideration of iron substrate nanocrystalline structure can help to elucidate the coexistence of different iron nitrides during the nitriding process. The average size of iron crystallites in a fresh sample is about $30 \mathrm{~nm}$. However, it is obvious that smaller as well as bigger than average crystallites exist. Small iron crystallites should transform into consecutive iron nitrides before the bigger ones. As a result small crystallites might be converted into $\varepsilon-\mathrm{Fe}_{\mathrm{x}} \mathrm{N}$ while big crystallites are still not completely transformed into $\gamma^{\prime}-\mathrm{Fe}_{4} \mathrm{~N}$. In this way different iron nitride phases can be present in the sample which can be explained by the XRD observations.

In an effort to understand the influence of the nitriding potential on the kinetics of iron nitriding, the experiments with a varying partial pressure of ammonia in the gas delivered to the reactor were also carried out. The nitriding mixtures were produced by the decomposition of ammonia in the pre-reactor. A series of nitriding experiments for the temperature range $350-500^{\circ} \mathrm{C}$ was carried out, where partial pressure of ammonia in the reaction space varied from about 0.2 bar to 0.9 bar. The reaction rate was calculated as a slope of linear sections of the obtained TG curves. In Fig. 5 the results obtained at $400^{\circ} \mathrm{C}$ are shown. Each stage of nitriding, ascribed by equations $(1-3)$, is marked separately. For each stage a linear dependence can be drawn. Moreover, the minimal partial pressure of ammonia is required to initiate the formation of a given iron nitride. Taking it into account a simple equation of the reaction rate is proposed below:

$r_{a}^{F e_{x} N}=k_{a}^{F e_{x} N} \cdot\left(p_{N_{3}}-p_{0, N H_{3}}^{F e_{x} N}\right)$

where: $r_{a}^{F e_{x} N}$ is a reaction rate for a given nitriding stage leading to $\mathrm{Fe}_{\mathrm{x}} \mathrm{N}, k_{a}^{F e_{x} N}$ is a reaction rate constant for the given nitriding stage leading to $\mathrm{Fe}_{\mathrm{X}} \mathrm{N}, p_{\mathrm{NH}_{3}}$ denotes the partial pressure of ammonia at the outlet of the reactor and $p_{0, N H_{3}}^{F e_{x} N}$ is the minimal partial pressure of ammonia required to initiate the formation of the given phase $\mathrm{Fe}_{\mathrm{x}} \mathrm{N}$.

The analysis of the collected data for the temperature range from $350^{\circ} \mathrm{C}$ to $500^{\circ} \mathrm{C}$ utilizing the equation (4) enable one to calculate the reaction rate constants for each experimental temperature (Fig. 6). In that way, an Arrhenius plot for three stages of iron nitriding is constructed. Apparent activation energy for each process has

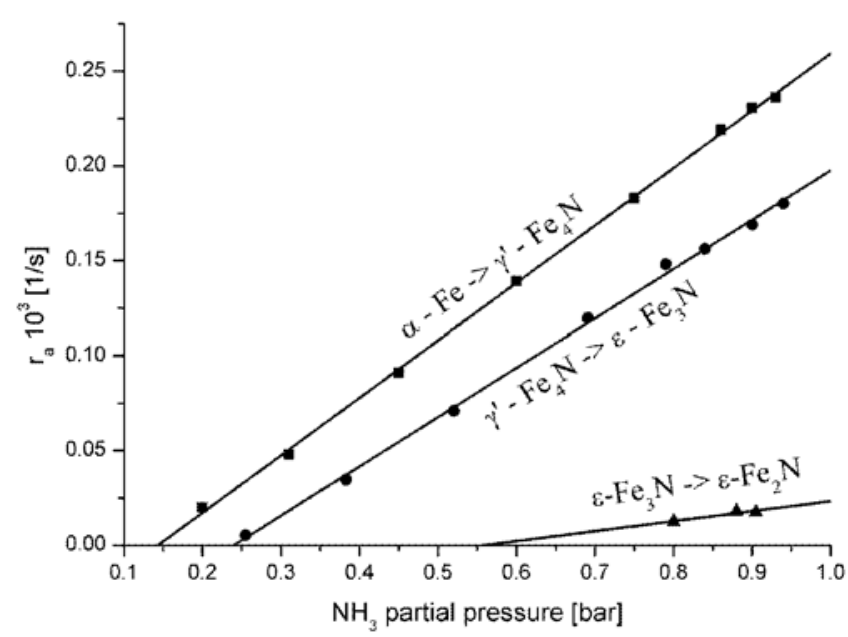

Figure 5. The rate of iron nitrides formation vs. ammonia partial pressure at $400^{\circ} \mathrm{C}$ for each stage of that process

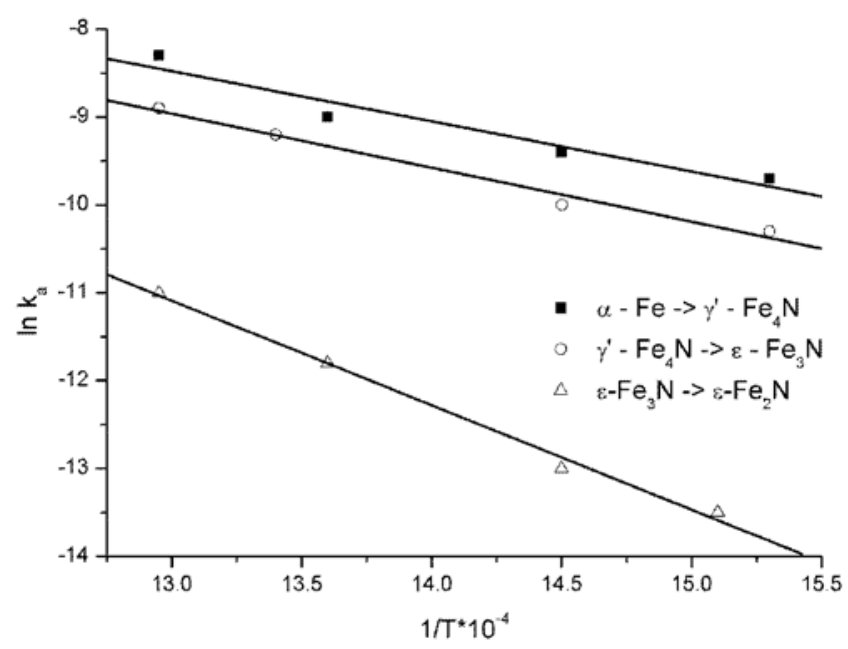

Figure 6. Arrhenius plot for the formation of different iron nitrides

been calculated and is shown in Table 1. The apparent activation energy for the reactions (1) and (2) is quite similar, however, the relevant value for the reaction (3) is more than two times higher.

At least two phenomena can account for the difference in the apparent activation energy of the observed nitriding stages: (1) the diffusion of nitrogen in iron and iron nitrides and (2) the adsorption of ammonia on the surface of these species. It is generally accepted that the diffusion of nitrogen atoms in iron and iron nitrides is the limiting step of the monolithic materials nitriding ${ }^{30-32}$. According to literature ${ }^{33}$ diffusion of nitrogen in iron and iron nitrides will slow down in a sequence: $\alpha-\mathrm{Fe}>\gamma^{\prime}-\mathrm{Fe}_{4} \mathrm{~N}$ $>\varepsilon-\mathrm{Fe}_{\mathrm{x}} \mathrm{N}$. In the case of thin films and presumably nanocrystalline materials the dissociative adsorption of ammonia on iron surface is considered as the limiting step of the process ${ }^{\mathbf{1 0}, \mathbf{3 4}, \mathbf{3 5}}$. The adsorption is dependent on the structure of the surface on which it takes place. Therefore, the phase transitions giving rise to the surface reconstructions need to be considered. First two reactions, (1) and (2), occur on $\alpha$-Fe and $\gamma^{\prime}-\mathrm{Fe}_{4} \mathrm{~N}$ which has cubic lattice though the former is bcc and the latter is fcc with

Table 1. Apparent activation energy for different nitriding stages

\begin{tabular}{|l|c|c|c|}
\hline Reaction & $\alpha-\mathrm{Fe} \rightarrow \gamma^{\prime}-\mathrm{Fe}_{4} \mathrm{~N}$ & $\gamma^{\prime}-\mathrm{Fe}_{4} \mathrm{~N} \rightarrow \varepsilon-\mathrm{Fe}_{3} \mathrm{~N}$ & $\varepsilon-\mathrm{Fe}_{3} \mathrm{~N} \rightarrow \varepsilon-\mathrm{Fe}_{2} \mathrm{~N}$ \\
\hline Apparent activation energy [kJ/mol] & $38 \pm 7$ & $43 \pm 4$ & $100 \pm 6$ \\
\hline
\end{tabular}


lattice constants $0.287 \mathrm{~nm}$ and $0.380 \mathrm{~nm}^{8}$, respectively. The reaction (3) is just a saturation of $\varepsilon-\mathrm{Fe}_{x} \mathrm{~N}$ from stoichiometry $\mathrm{Fe}_{3} \mathrm{~N}$ to $\mathrm{Fe}_{2} \mathrm{~N}$. This iron nitride has hcp structure with much bigger lattice constants. Thus, the expansion of the substrate lattice during nitriding resulting in the broadening of iron - iron distances can be regarded as a reason for the observed high apparent activation energy of the reaction (3). However, basing on the present results neither the diffusion nor adsorption processes can be excluded from the consideration. Still more research is needed to solve the problem.

\section{CONCLUSIONS}

The extended study on iron nitriding at different reaction temperatures and under different nitriding potential leads to the following conclusions:

1. Final nitrogen concentration after nitriding process, hence, iron nitride being a product of that process depends on the nitriding potential and obeys the thermodynamics of Fe-N system.

2. During nitriding of nanocrystalline iron three stages of the process were observed. These stages were ascribed to the following schematic reactions: (1) $\alpha-\mathrm{Fe} \rightarrow$ $\gamma^{\prime}-\mathrm{Fe}_{4} \mathrm{~N},(2) \gamma^{\prime}-\mathrm{Fe}_{4} \mathrm{~N} \rightarrow \varepsilon-\mathrm{Fe}_{3} \mathrm{~N}$ and (3) $\varepsilon-\mathrm{Fe}_{3} \mathrm{~N} \rightarrow$ $\varepsilon-\mathrm{Fe}_{2} \mathrm{~N}$.

3. The linear dependence of the nitriding rate on the ammonia partial pressure was observed for each stage of the process. The surface reaction (ammonia decomposition) is supposed to be a limiting step of that process.

\section{LITERATURE CITED}

1. VDI (1990). VDI - Lexikon Werkstofftechnik. Dusseldorf: VDI-Verlag.

2. Bell, T. (1977). Source Book on Nitriding (pp. 266 - 278). Metals Park: American Society of Metals.

3. Mongis, J., Peyre, J. P., \& Tournier, C. (1984). Nitriding of microalloyed steels. Heat Treatment of Metals. 11(3), 71 - 75.

4. (2006). Nanomaterials Handbook. Boca Raton: CRC/Taylor \& Francis.

5. Gu, J. F., Bei, D. H., Pan, J. S., Lu, J., \& Lu, K. (2002). Improved nitrogen transport in surface nanocrystallized lowcarbon steels during gaseous nitridation. Materials Letters. 55, $340-343$.

6. Tong, W. P., Tao, N. R., Wang, Z. B., Zhang, H. W., Lu, J., \& Lu, K. (2004). The formation of $\varepsilon-\mathrm{Fe}_{3-2} \mathrm{~N}$ phase in a nanocrystalline Fe. Scripta Materialia. 50, 647-650.

7. Tong, W. P., Liu, C. Z., Wang, W., Tao, N. R., Wang, Z. B., Zuo, L., \& He, J. C. (2007). Gaseous nitriding of iron with a nanostructured surface layer. Scripta Materialia. 57, 533 536.

8. Schaaf, P. (2002). Laser nitriding of metals. Prog. Mater. Sci.. 47, 1 - 161 .

9. Nishimaki, K., Ohmae, S., Yamamoto, T. A., \& Katsura, M. (1999). Formation of iron-nitrides by the reaction of iron nanoparticles with a stream of ammonia. Nanostructured Materials. 12, 527 - 530.

10. Inia, D. K., Vredenberg, A. M., Habraken, F. H. P. M., \& Boerma, D. O. (1999). Nitrogen uptake and rate-limiting step in low-temperature nitriding of iron. Journal of Applied Physics. 86(2), 810 - 816.

11. Wu, X. L., Zhong, W., Tang, N. J., Jiang, H. Y., Liu, W., $\& \mathrm{Du}, \mathrm{Y}$. W. (2004). Magnetic properties and thermal stability of nanocrystalline $\varepsilon-\mathrm{Fe}_{3} \mathrm{~N}$ prepared by gas reduction-nitriding method. J. Alloy. Comp. 385, 294 - 297. DOI: 10.1016/ j.jallcom.2004.04.127.
12. Jiraskova, Y., Havlicek, S., Schneeweiss, O., Perina, V., \& Blawert, C. (2001). Characterization of iron nitrides prepared by spark erosion, plasma nitriding, and plasma immersion ion implantation. Journal of Magnetism and Magnetic Materials. 234, 477 - 488.

13. Lin, C.-K., Chen, G.-S., Chen, J.-S., Chin, T.-S., \& Lee, P.-Y. (2001). Characterization of iron nitride powders formed by mechanical alloying and atmospheric heat treatment techniques. J. Chin. Inst. Eng. 24(6), 755 - 762.

14. Schaaf, P. (1998). Iron nitrides and laser nitriding of steel. Hyperfine Interactions. 111, 113 - 119.

15. Shinno, H., Uehara, M., \& Saito, K. (1997). Synthesis of $\alpha$ "- $-\mathrm{Fe}_{16} \mathrm{~N}_{2}$ iron nitride by means of nitrogen-ion implantation into iron thin films. J. Mater. Sci. 32, 2255 - 2261.

16. Kunze, J. (1990). Nitrogen and carbon in iron and steel thermodynamics. Berlin: Akademie-Verlag.

17. Lakhtin, J. M., \& Kogan, J. D. (1976). Azotirovanie stali. Moskva: Masinostroenie.

18. Lehrer, E. (1930). The equilibrium, iron - hydrogen ammonia. Z. Electrochem. 36, 383 - 392.

19. Wohlschloegel, M., Welzel, U., \& Mittemeijer, E. J. (2007). Unexpected formation of $\varepsilon$ iron nitride by gas nitriding of nanocrystalline $\alpha$-Fe films. Applied Physics Letters. 91, 141901.

20. Arabczyk, W., \& Wróbel, R. (2003). Study of the Kinetics of Nitriding of Nanocrystalline Iron using TG and XRD methods. Sol. State Phenom. 94, 185 - 188.

21. Cao, M., Wang, R., Fang, X., Cui, Z., Chang, T., \& Yang, H. (2001). Preparing $\gamma^{\prime}-\mathrm{Fe}_{4} \mathrm{~N}$ ultrafine powder by twice-nitriding method. Powder Technology. 115, 96-98.

22. Arabczyk, W., \& Jakrzewska, M. (1995). The nitriding kinetics of fine-crystalline $\alpha-\mathrm{Fe}$. In: Advanced materials and technologies: $14^{\text {th }}$ International Scientific Conference (pp. 21 24). Gliwice: Committee of Metallurgy of the Polish Academy of Science.

23. Arabczyk, W., \& Wróbel, R. (2003). Study of the kinetics of reduction of the nanocrystalline iron nitrides. Annals of Polish Chemical Society. 3(3), 1065 - 1069.

24. Opalińska, A., Leonelli, C., Lojkowski, W., Pielaszek, R., Grzanka, E., Chudoba, T., Matysiak, H., Wejrzanowski, T., \& Kurzydłowski, K. J. (2006). Effect of Pressure on Synthesis of Pr-Doped Zirconia Powders Produced by Microwave-Driven Hydrothermal Reaction. J. Nanomater. 2006(Article ID 98769), 1 - 8. DOI: $10.1155 / J N M / 2006 / 98769$.

25. Schloegl, R. (1991). In: J. R. Jennings, Catalytic Ammonia Synthesis (p. 19). New York: Plenum Press.

26. Du Marchie van Voorthuysen, E. H., Chechenin, N. C., \& Boerma, D. O. (2002). Low-Temperature Extention of the Lehrer Diagram and the Iron-Nitrogen Phase Diagram. Metallurgical and Materials Transactions A: Physical Metallurgy and Materials Science. 33A, 2593 - 2598.

27. Arabczyk, W., \& Zamłynny, J. (1999). Study of the ammonia decomposition over iron catalysts. Catal. Lett. 60(3), $167-171$.

28. Love, K. S., \& Emmett, P. H. (1941). The Catalytic Decomposition of Ammonia over Iron Synthetic Ammonia Catalysts. J. Amer. Chem. Soc. 63, 3297 - 3308.

29. Logan, S. R., Moss, R. L., \& Kemball, C. (1958). The Catalytic Decomposition of Ammonia on Evaporated Iron Films. Trans. Farad. Soc. 54, 922 - 930.

30. Pulkkinen, R. E. E. (1982). Kinetics of nitridation of $\alpha$-irons containing chromium, molybdenum, and silicon in ammonia - hydrogen mixtures. Metal Science. 16, 37 - 40.

31. Rosendaal, H. C. F., Colijn, P. F., \& Scheaf, P. J. (1983). The developement of nitrogen concentration profiles of nitriding iron. Metal. Trans. 14, 395 - 399.

32. Keddam, M., Djeghlal, M. E., \& Barrallier, L. (2005). A simple diffusion model for the growth kinetics of $\gamma^{\prime}$ iron nitride on the pure iron substrate. Appl. Surf. Sci. 242, 369 374. DOI: $10.1016 /$ j.apcusc.2004.09.003. 
33. Keddam, M., Djeghlal, M. E., \& Barrallier, L. (2004). A diffusion model for simulation of bilayer growth $\left(\varepsilon / \gamma^{\prime}\right)$ of nitrided pure iron. Mater. Sci. Eng. A. 378, 475-478. DOI: 10.1016/j.msea.2003.11.066.

34. Grabke, H. J. (1968). Reaction of ammonia, nitrogen, and hydrogen on the surface of iron. II. Kinetics of iron nitridation with nitrogen and nitrogen desorption. Ber. Bunsenges. Phys. Chem. 4, 533 - 543.

35. Grabke, H. J. (1973). Kinetics of nitriding iron as a function of the oxygen activity of the gas. Archiv. Eisenhut. 44, $603-608$. 